\title{
Body composition of piglets exhibiting different growth rates
}

\author{
Alva D. Mitchell', Timothy G. Ramsay' ${ }^{1}$, Thomas J. Caperna' and Armin M. Scholz ${ }^{2}$ \\ 'Agricultural Research Service, U.S. Department of Agriculture, Beltsville, MD, USA, ${ }^{2}$ Livestock Center, University \\ Munich, Oberschleißheim, Germany
}

\begin{abstract}
The growth and composition of the neonatal pig is of interest because of potential impact on subsequent growth and finally, composition at market weight. The purpose of this study was to compare at weaning the growth and body composition of the largest and smallest pigs from each of 38 litters. At weaning $(27 \pm 1.7 \mathrm{~d})$ the largest $(9.3 \pm 1.1 \mathrm{~kg})$ and smallest $(6.2 \pm 1.5 \mathrm{~kg})$ pigs were selected for body composition measurement by dual energy X-ray absorptiometry (DXA). The body composition of the largest pigs consisted of $38 \%$ more fat, $32 \%$ more lean, and $29 \%$ more bone mineral content $(P<0.001)$. However, when expressed as a percentage of body weight, there was no difference in the fat, lean or bone mineral content content of the two groups of pigs $(P>0.05)$. A second study consisted of 12 pairs of pigs from 8 litters that were selected on the basis of having the same birth weight, but one pig out gaining the other by at least $50 \mathrm{~g} /$ day. At 21 days of age the selected pigs were scanned by DXA. For both groups combined, the correlation ( $r$ ) between body weight and lean mass was 0.99 , between body weight and fat mass it was 0.87 , and between body weight at birth and body weight at weaning it was 0.56 . The results of these studies revealed that, at weaning, the fastest and slowest growing pigs had similar proportions of fat, lean and bone mineral and, consistent with previous results, the rates of both fat and lean deposition were highly correlated $(P<0.001)$ with total body growth rate.
\end{abstract}

Keywords: piglets, body composition, growth rate, dual energy X-ray absorptiometry

\section{Introduction}

The neonatal growth period of the pig, from birth to weaning, is a critical phase in pork production. Genetic selection for larger litter size has also resulted in a reduction in mean piglet birth weight, increased within-litter variation in birth weight and a rise in the proportion of low birth weight piglets $(<1.0 \mathrm{~kg}$ ) within these large litters (Milligan et al. 2002, Quiniou et al. 2002). Birth weight in pigs has been linked to differences in both growth rate and body composition. The survival of low birth weight pigs in particular may depend on energy stores in the body (Girard 1981). Based on chemical analysis of the whole body at birth, Rehfeldt \& Kuhn (2006) reported that low birth weight pigs have less fat and protein and more water than their littermates. Low birth weight pigs exhibit a $15 \%$ to $30 \%$ lower growth rate (compared to medium and high birth weight pigs) in the first month of postnatal life (Campbell \& Dunkin 1982, Wolter et al. 2002, Poore \& Fowden 2004, Gondret et al. 2005 
and 2006, Škorjanc et al. 2007). The growth and composition of the neonatal pig is also of interest because of potential impact on subsequent growth and composition (Young \& Sharma 1973, Mahan \& Lepine 1991). Studies have found that factors such as birth weight (Powell \& Aberle 1980, Poore \& Fowden 2004) and nutrition during the neonatal period (Pond et al. 1965, Campbell \& Dunkin 1983) can affect both growth and composition during the post weaning period. Increasingly, the low birth weight pig is also of interest as a model in studies of intrauterine growth retardation (IUGR) and the implications regarding human health and obesity (Vuguin 2007, Morise et al. 2009, Morise et al. 2011).

Only a few studies have measured the changes in body composition of the pig during the suckling period (Manners \& McCrea 1963, Campbell \& Dunkin 1983, Noblet \& Etienne 1987, Dunshea et al. 2003). In a previous study that evaluated the growth and body composition of entire litters during the period of growth from birth to $4 \mathrm{~kg}$, the rates of both fat and lean deposition were linear and highly correlated with total body growth, however all three (fat, lean, and total body growth) were found to have a low correlation with birth weight (Mitchell et al. 2012). In addition to the low birth weight pigs, frequently within a litter there are other pigs that grow at a rate well below the average during the period between birth and weaning. The purpose of the present study was to examine differences in body composition of faster and slower growing pigs, in particular, contrasting the largest and smallest pigs of the litter at weaning and also pigs of the same birth weight but exhibiting differences in growth rate.

\section{Methods}

The pigs used in this study were from 37 litters (of 29 sows) of a Large White $\times$ Poland China $\times$ Landrace cross. At weaning ( $27 \pm 2.6$ days) the entire litter was weighed and the largest and smallest pigs from each litter were selected for body composition measurement. The litter size at weaning ranged from 6 to 16 (average $\pm S D=9.6 \pm 2.3$ ). Runt (IUGR=intrauterine growth retarded) piglets were excluded from the study. Although not paired by sex, each group consisted of 22 females and 15 males (entire). Body composition was measured by dual energy X-ray absorptiometry (DXA) scanning which measures total body fat, lean and bone mineral content plus bone mineral density. In order to perform the DXA scan the pigs were sedated using an intramuscular injection of $5.0 \mathrm{mg}$ ketamine, $0.80 \mathrm{mg}$ tiletamine, $0.80 \mathrm{mg}$ zolazepam and $3.33 \mathrm{mg}$ xylazine per $\mathrm{kg}$ body weight. The scanning was performed using a DXA (GE Lunar Prodigy, GE Healthcare, Little Chalfont, UK) operating in the Small Animal Mode (ver. 8.10). The DXA reported fat and lean contents were corrected based on previous calibration studies using similar sized pigs and the scan procedures (Kovner et al. 2010, Mitchell et al. 2012). The correction factor applied to the DXA fat measurement was as follows: \%Fat $=0.9608+(0.7135 \times$ DXA Fat $\%)$. The DXA lean measurement was then adjusted for the difference in the observed and calculated fat measurements. Total body protein was predicted by the following equation: grams of protein $=0.188 \times$ DXA lean (Mitchell et al. 1998). By estimating the fat and lean content of the pigs at birth using a modified function from the quantitative magnetic resonance data of Mitchell et al. (2012):

$$
\begin{aligned}
& \text { fat } \%=-3.4+7.34449 \times \text { birth weight }-\left(0.679082 \times\left[\text { birth weight }^{2}\right]\right) ; \\
& \text { lean } \%=100 \%-\text { fat } \%-3 \%
\end{aligned}
$$

the fat and lean tissue accretion rates were calculated for each group of pigs individually. 
A second study consisted of 12 pairs of pigs from 8 litters. These pigs were selected on the basis of having the same birth weight, but one pig out gaining the other by at least $50 \mathrm{~g} /$ day, thus being substantially ( $>10 \%$ ) larger than the other at 21 days of age. At 21 days of age the selected pigs were scanned by DXA as described above. Experimental animal protocols used in this study were approved by the Beltsville Area Institutional Animal Care and Use Committee.

The SAS software package v9.3 (SAS Institute Inc., Cary, NC, USA) provided the tool for data analysis using a mixed model procedure with the following structure for the variables of trial 1:

$$
y_{i j k}=\mu+L G_{i}+G_{j}+B W_{i j k}+I_{i j k}+e_{i j k}
$$

where $y_{i j k}$ is the observation, $\mu$ is the expected value of $y_{i j k^{\prime}} L G_{i}$ is the Litter Group $(i=1,2), G_{j}$ is the gender $(j=1,2), B W_{i j k}$ is the number of weaned piglets as covariate, $I_{i j k}$ is the litter as random effect and $e_{i j k}$ is the residual error.

REML (restricted maximum likelihood) was used as estimation method and Satterthwaite as degrees of freedom method followed by the t-Test procedure. A similar model served for the variance analysis of the variables in trial 2, though the number of weaned piglets was not included as covariate anymore. Due to the pair-wise structure, the results were affected equally for both groups.

Correlation coefficients were calculated as the Pearson product moment correlations for pairs of variables. $P$-values of $<0.05$ were considered statistically significant.

\section{Results}

At weaning, the largest pig from each litter outweighed the smallest pig from the same litter by an average of $3.15 \mathrm{~kg}$ (Table 1). The smallest pigs also weighed less at birth, although the percentage difference at birth $(-19.7 \%)$ was less than the difference at weaning $(-35.5 \%)$. The greater percentage difference at weaning was the result of a $39 \%$ lesser growth rate between birth and weaning by the smallest pig.

Table 1 also shows a comparison of the DXA measurements of body composition of the largest and smallest pigs of each litter. Consistent with the difference in body weight, at weaning the lean mass and bone mineral content were $34.3 \%$ and $33.7 \%$ less in the smallest pigs compared to the largest pigs. However, the lightest pigs had $44.8 \%$ less fat than the heaviest pigs. When the fat and lean content were expressed as a percentage of the total body, the lightest pigs had $18.7 \%$ less fat and $2.7 \%$ more lean compared to the heaviest pigs. By estimating the fat and lean content of the pigs at birth (using the modified function of Mitchell et al. 2012) the fat and lean tissue accretion rates were calculated for each group of pigs. From birth to weaning, the lightest pigs had a $45.7 \%$ lower fat accretion rate and a $37.6 \%$ lower lean accretion rate as reflected by similar differences in the fat and lean content at weaning. The amounts of both total weight gain and protein gain relative to fat gain was considerably higher in the smallest pigs compared to the heaviest pigs ( $105.3 \%$ and $125.4 \%$ respectively). The relationships between the rate of total body growth and the rates of fat and lean growth are shown in Figure 1. 
Table 1

Pair-wise comparison of measurements of largest and smallest pigs of each litter (Least squares means \pm SEE, $\mathrm{n}=74)$

\begin{tabular}{lcccc}
\hline Measurement & Largest pigs & Smallest pigs & Difference $^{1}$ & \% Difference \\
\hline Birth weight, kg & $1.62 \pm 0.05$ & $1.30 \pm 0.05$ & $-0.32(P<0.001) \pm 0.05$ & -19.7 \\
Weaning weight, kg/day 27 & $8.87 \pm 0.23$ & $5.73 \pm 0.22$ & $-3.15(P<0.001) \pm 0.25$ & -35.5 \\
Gain, g/day & $268 \pm 7.83$ & $164 \pm 7.53$ & $-104(P<0.001) \pm 8.93$ & -38.8 \\
Fat, \% & $11.91 \pm 0.53$ & $9.52 \pm 0.51$ & $-2.39(P=0.002) \pm 0.61$ & -18.7 \\
Fat, g & $1040 \pm 50.6$ & $571 \pm 48.9$ & $-466(P<0.001) \pm 53.0$ & -44.8 \\
Lean, \% & $88.09 \pm 0.53$ & $90.48 \pm 0.51$ & $+2.39(P=0.002) \pm 0.60$ & +2.7 \\
Lean, g & $7675 \pm 192$ & $5045 \pm 185$ & $-2630(P<0.001) \pm 206$ & -34.3 \\
Bone mineral content, g & $190 \pm 5.4$ & $126 \pm 5.2$ & $-64(P<0.001) \pm 5.1$ & -33.7 \\
Bone mineral density, g/cm ${ }^{2}$ & $0.382 \pm 0.006$ & $0.323 \pm 0.006$ & $-0.059(P<0.001) \pm 0.006$ & -18.0 \\
Fat gain, g/day & $35 \pm 1.9$ & $19 \pm 1.9$ & $-16(P<0.001) \pm 2.0$ & -45.7 \\
Lean gain, g/day & $229 \pm 6.0$ & $143 \pm 5.7$ & $-86(P<0.001) \pm 7.0$ & -37.6 \\
Protein gain, g/day & $43 \pm 1.1$ & $27 \pm 1.1$ & $-16(P<0.001) \pm 1.3$ & -37.2 \\
Total gain/fat gain & $7.41 \pm 2.05$ & $15.21 \pm 1.96$ & $-7.80(P=0.006) \pm 2.69$ & +105.3 \\
Protein gain/fat gain & $1.18 \pm 0.39$ & $2.66 \pm 0.37$ & $+1.48(P=0.005) \pm 0.51$ & +125.4 \\
\hline
\end{tabular}

'Difference, smallest compared to largest pig.
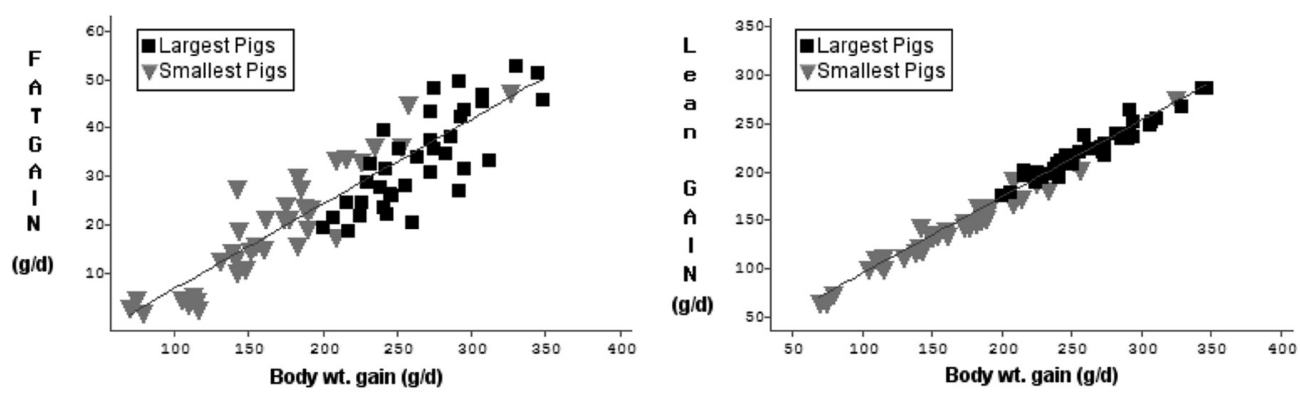

Figure 1

The relationship between the rates of fat or lean gain and the rate of total body weight gain, comparing the largest and smallest pigs of each litter at weaning.

The correlation between growth and composition parameters for the largest and smallest littermates is shown in Table 2 . Weaning weight was more highly correlated with the growth and body composition parameters than was birth weight. There was not a significant correlation $(P>0.05)$ between birth weight and the percentage of total body fat or lean at the time of weaning and between birth weight and tissue weight gains. Total body lean percentage was negatively correlated with all other parameters. The DXA measure of bone mineral content was highly correlated $(r \geq 0.79)$ with weaning weight, lean mass and bone mineral density. 
Table 2

Correlation ( $r$ ) between growth and composition parameters at the time of weaning (day 27) for the largest and smallest littermates

\begin{tabular}{|c|c|c|c|c|c|c|c|c|c|c|c|}
\hline & $\begin{array}{c}\text { Birth } \\
\text { weight }\end{array}$ & $\begin{array}{c}\text { Weaning } \\
\text { weight }\end{array}$ & $\begin{array}{l}\text { WT gain, } \\
\text { g/day }\end{array}$ & $\begin{array}{c}\text { Fat, } \\
\%\end{array}$ & $\begin{array}{c}\text { Fat, } \\
\text { g }\end{array}$ & $\begin{array}{l}\text { Lean, } \\
\mathrm{g}\end{array}$ & $\begin{array}{c}\text { Lean, } \\
\%\end{array}$ & $\begin{array}{c}\text { Fat gain, } \\
\text { g/day }\end{array}$ & $\begin{array}{c}\text { Lean gain, } \\
\text { g/day }\end{array}$ & $\begin{array}{c}\mathrm{BMC} \\
\mathrm{g}\end{array}$ & $\begin{array}{l}\text { BMD, } \\
\mathrm{g} / \mathrm{cm}^{2}\end{array}$ \\
\hline Birth weight & & 0.39 & $0.16^{\mathrm{ns} 1}$ & $0.16^{\mathrm{ns}}$ & 0.33 & 0.37 & $-0.16^{\mathrm{ns}}$ & $0.15^{\mathrm{ns}}$ & $0.17^{\mathrm{ns}}$ & 0.50 & $0.29^{\text {ns }}$ \\
\hline Weaning weight & $0.32^{\text {ns }}$ & & 0.73 & $0.24^{\text {ns }}$ & 0.68 & 0.97 & $-0.24^{\text {ns }}$ & & 0.78 & 0.85 & 0.54 \\
\hline WT gain, g/day & $0.14^{\mathrm{ns}}$ & 0.93 & & 0.54 & 0.75 & 0.60 & -0.54 & 0.80 & 0.96 & 0.47 & 0.38 \\
\hline Fat, $\%$ & $-0.04^{\mathrm{ns}}$ & 0.71 & 0.80 & & 0.87 & $0.02^{\text {ns }}$ & -1.00 & 0.93 & 0.33 & $0.20^{\text {ns }}$ & 0.49 \\
\hline Fat, g & $0.13^{\mathrm{ns}}$ & 0.89 & 0.91 & 0.93 & & 0.50 & -0.87 & 0.91 & 0.63 & 0.58 & 0.63 \\
\hline Lean, $\mathrm{g}$ & 0.35 & 0.98 & 0.87 & 0.62 & 0.83 & & $-0.01^{\mathrm{ns}}$ & $0.23^{\text {ns }}$ & 0.71 & 0.84 & 0.44 \\
\hline Lean, \% & $0.04^{\text {ns }}$ & -0.71 & -0.80 & -1.00 & -0.93 & -0.62 & & -0.93 & -0.33 & $-0.20^{\mathrm{ns}}$ & -0.49 \\
\hline Fat gain, g/day & $0.03^{\text {ns }}$ & 0.82 & 0.93 & 0.94 & 0.98 & 0.74 & -0.94 & & 0.64 & $0.29^{\text {ns }}$ & 0.46 \\
\hline Lean gain, g/day & $0.17^{\mathrm{ns}}$ & 0.95 & 0.99 & 0.75 & 0.89 & 0.92 & -0.75 & 0.89 & & 0.51 & $0.32^{\text {ns }}$ \\
\hline $\mathrm{BMC}, \mathrm{g}$ & 0.34 & 0.97 & 0.86 & 0.70 & 0.86 & 0.96 & -0.70 & 0.77 & 0.88 & & 0.79 \\
\hline $\mathrm{BMD}, \mathrm{g} / \mathrm{cm}^{2}$ & 0.35 & 0.88 & 0.79 & 0.70 & 0.82 & 0.86 & -0.70 & 0.73 & 0.79 & 0.95 & \\
\hline
\end{tabular}

WT: weight, BMC: bone mineral content, BMD: bone mineral density, 'ns: not significant at $P<0.05$, all others significant at $P<0.05$.above diagonal $=$ largest piglet group, below diagonal $=$ smallest piglet group

Pair-wise comparisons of measurements of pigs from same litter with similar birth weights but different body weights at 21 days of age are shown in Table 3. Despite having the same birth weight, at 21 days of age the one set of littermates out weighed the others by an average of $2.8 \mathrm{~kg}$. This difference in weight was due to a $30.3 \%$ difference in growth rate. DXA measurements revealed that the slower growing pigs had $40.0 \%$ less fat and $19.4 \%$ less lean. When the fat and lean content were expressed as a percentage of the total body, the slower growing pigs had $26.3 \%$ less fat and $4.2 \%$ more lean compared to the faster growing pigs. From birth to 21 days of age, the slower growing pigs had a $44.7 \%$ lower fat accretion rate and a $26.0 \%$ lower lean accretion rate. As with the first study, the amounts of both total weight gain and protein gain relative to fat gain was higher in the slower growing (smaller pigs) compared to the faster growing (heavier pigs).

For both groups combined ( $n=100$, data not shown), the correlation ( $r$ ) between body weight and lean mass was 0.99 , between body weight and fat mass it was 0.87 , and between body weight at birth and body weight at weaning it was 0.56 .

Table 3

Pair-wise comparison of measurements of pigs from same litter with similar birth weights but $>10 \%$ different body weights at 21 days of age (least squares means $\pm S E E, n=24$ )

\begin{tabular}{lcccc}
\hline Measurement & Faster growing & Slower growing & Difference $^{1}$ & \% Difference \\
\hline Birth weight, $\mathrm{kg}$ & $1.42 \pm 0.08$ & $1.45 \pm 0.08$ & $+0.03(P=0.36) \pm 0.03$ & +2.1 \\
21 day weight, kg & $6.23 \pm 0.22$ & $3.43 \pm 0.22$ & $-2.8(P<0.001) \pm 0.20$ & -44.9 \\
Gain, g/day & $231 \pm 12$ & $161 \pm 12$ & $-70(P<0.001) \pm 8$ & -30.3 \\
Fat, \% & $13.68 \pm 0.76$ & $10.08 \pm 0.77$ & $-3.60(P<0.001) \pm 0.63$ & -26.3 \\
Fat, g & $870 \pm 66$ & $521 \pm 66$ & $-348(P<0.001) \pm 40$ & -40.0 \\
Lean, \% & $86.32 \pm 0.76$ & $89.92 \pm 0.77$ & $+3.60(P<0.001) \pm 0.63$ & +4.2 \\
Lean, g & $5501 \pm 263$ & $4435 \pm 263$ & $-1066(P<0.001) \pm 132$ & -19.4 \\
Bone mineral content, g & $142 \pm 9$ & $111 \pm 8$ & $-31(P<0.001) \pm 4$ & -21.8 \\
Bone mineral density, g/cm ${ }^{2}$ & $0.351 \pm 0.013$ & $0.307 \pm 0.013$ & $-0.044(P<0.001) \pm 0.006$ & -12.5 \\
Fat gain, g/day & $38 \pm 3$ & $21 \pm 3$ & $-17(P<0.001) \pm 2$ & -44.7 \\
Lean gain, g/day & $200 \pm 11$ & $148 \pm 11$ & $-52(P<0.001) \pm 6$ & -26.0 \\
Total gain/fat gain & $6.29 \pm 0.74$ & $9.05 \pm 0.74$ & $+2.76(P<0.001) \pm 0.61$ & +43.9 \\
Protein gain/fat gain & $1.02 \pm 0.13$ & $1.56 \pm 0.13$ & $+0.54(P=0.001) \pm 0.11$ & +52.9 \\
\hline
\end{tabular}

'Difference, smallest compared to largest pig. 


\section{Discussion}

Even though the pigs in the first study were not selected on the basis of birth weight, the selection of the largest and smallest pigs at weaning resulted in the retrospective selection of two groups of pigs with a significant difference in birth weight. This is in agreement with the report by Quiniou et al. (2002) that the individual body weight of pigs at weaning was highly correlated with birth weight. The same study also indicated that small birth weight piglets $(<1.0 \mathrm{~kg})$ were, to some extent, able to catch up in growth with larger pigs during the suckling period and that proportionally to birth weight, lighter piglets had higher relative weight gain (gain/birth weight). However, in the present study, because pigs were essentially selected on the basis of differences in growth rate, the heavier pigs also had a higher relative weight gain compared to the lighter pigs (5.48 vs. $4.41, P<0.001)$.

In the first study reported here, the $268 \mathrm{~g} /$ day growth rate observed for the heaviest pigs is consistent with the 250 to $270 \mathrm{~g} /$ day reported for modern genotypes (King et al. 1999). In the second study, the growth rate for the faster growing pigs was somewhat lower $(231 \mathrm{~g} /$ day), however those pigs were only measured up to 21 days of age compared to $27 \pm 2.6$ days in the first study. In both studies the growth rate of the slower growing pigs (164 and $161 \mathrm{~g} /$ day) was considerably less than the rate reported by King et al. (1999).

The measurements of body composition in the two studies reported here were consistent in terms of the differences in fat and lean content when comparing faster to slower growing pigs. The differences in absolute quantities of fat and lean were somewhat greater in the first study where the largest pig was compared to the smallest pig as opposed to the second study where pigs of similar birth weight were contrasted based on differences in growth rate to three weeks of age. However the differences in the rates of fat gain were nearly identical for the two studies as was the rate of lean gain for the slower growing pigs. The rates of fat and lean gain for the largest/faster growing pigs in the first and second studies were 35 and $38 \mathrm{~g} /$ day and 229 and $200 \mathrm{~g} /$ day respectively. In comparison, also using dual energy X-ray absorptiometry (DXA) Dunshea et al. (2003) measured a fat deposition rate of $52.7 \mathrm{~g} / \mathrm{d}$ and a lean deposition rate of $211 \mathrm{~g} /$ day for pigs with a growth rate of $258 \mathrm{~g} / \mathrm{d}$ between one and 21 days of age.

In agreement with an earlier study using quantitative magnetic resonance to measure changes in body composition of piglets between birth and $4 \mathrm{~kg}$ (Mitchell et al. 2012), the correlation $(r)$ between the rates of fat and lean deposition in the first study was 0.64 for the largest piglets and 0.87 for the smallest piglets $(P<0.001)$. In the first and second studies reported here (see Tables 1 and 3 ), the ratio of total body growth rate to the rate of fat deposition was 7.4 and 6.3 (respectively) for the faster growing pigs and 15.2 and 9.1 (respectively) for the slower growing pigs. In comparison, a ratio of 5.6 was reported by Mitchell et al. (2012) and a ratio of 6.9 was reported by Noblet \& Etienne (1987). The relationship between the rate of total body growth and the rate of fat growth is better illustrated in Figure 1. From this figure it appears that the overall relationship between the rate of total body growth and the rate of fat growth was similar for the slower and faster growing pigs. However, with the slower growing pigs, as the total body growth rate dropped to around $100 \mathrm{~g} / \mathrm{day}$; the rate of fat deposition approached zero, thus resulting in an increasingly higher ratio. For example, nine pigs from the slow growing group had a growth rate of $<120 \mathrm{~g} / \mathrm{day}$ and an average of 
33 for the ratio of total body growth rate to the rate of fat deposition. The same figure also shows that the overall relationship between the rate of total body growth and the rate of lean growth was similar for the slower and faster growing pigs; however, in this case as the rate of body growth dropped below $100 \mathrm{~g} /$ day, lean growth continued.

In the two studies reported here, the ratio of protein gain (estimated) to lipid gain was 1.18 and 1.02 (respectively) for the faster growing pigs and 2.66 and 1.56 (respectively) for the slower growing pigs. Again in comparison, a ratio of 0.93 was reported by Mitchell et al. (2012) and a ratio of 1.06 was reported by Noblet \& Etienne (1987). This ratio is influenced by the energy content of the diet (Campbell \& Dunkin 1983). In the study by Campell \& Dunkin (1983) for pigs growing from 1.8 to $6.5 \mathrm{~kg}$ while receiving adequate protein, as the energy intake increased there was a curvilinear increase in fat deposition - resulting in a curvilinear decrease in the ratio of protein gain to lipid gain, dropping from 3.31 to 0.90 .

In conclusion, results of this study revealed that, at weaning, the fastest and slowest growing pigs had different proportions of fat, lean, and bone mineral with a higher fat proportion for the fastest growing pigs. Consistent with previous results, the rates of both fat and lean deposition were highly correlated $(P<0.001)$ with total body growth rate. Thus, during the period between birth and weaning slower growing pigs, regardless of birth weight, deposited proportionally less fat and more lean when compared to their faster growing littermates. Other studies (Rehfeldt et al. 2008, Bérard et al. 2010) have found that low birth weight pigs tend to have a higher percentage of body fat at slaughter, indicating that these pigs deposit this additional fat between weaning and slaughter.

\section{References}

Bérard J, Kreuzer M, Bee G (2010) In large litters birth weight and gender is decisive for growth performance but less for carcass and pork quality traits. Meat Sci 86, 845-851

Campbell RG, Dunkin AC (1982) The effect of birth weight on the estimated milk intake, growth and body composition of sow-reared piglets. Anim Prod 35, 193-197

Campbell RG, Dunkin AC (1983) The effects of energy intake and dietary protein on nitrogen retention, growth performance, body composition and some aspects of energy metabolism of baby pigs. Br J Nutr 49, 221-230

Dunshea FR, Suster D, Kerton DJ, Leury BJ (2003) Exogenous porcine somatotropin administered to neonatal pigs at high doses can alter lifetime fat but not lean tissue deposition. $\mathrm{Br} J$ Nutr 89, 795-801

Girard J (1981) Fuel homeostasis during the perinatal period. In: Ritzén M, Aperia A, Hall K, Larssan A, Zetterberg A, Zetterstrom R (eds.) The Biology of Normal Human Growth. Raven Press, New York, NY, USA, 193-202

Gondret F, Lefaucheur L, Louveau I, Lebret B (2005) The long-term influences of birth weight on muscle characteristics and eating meat quality in pigs individually reared and fed during fattening. Arch Tierz (Special Issue) 48, 68-73

Gondret F, Lefaucheur L, Juin H, Louveau I, Lebret L (2006) Low birth weight is associated with enlarged muscle fiber area and impaired meat tenderness of the longissimus muscle in pigs. J Anim Sci 84, 93-103

King RH, Le Dividich J, Dunshea FR (1999) Lactation and neonatal growth. In: Kyriazakis I (ed.) A Quantitative Biology of the Pig. CAB International, Oxon, UK, 155-180

Kovner I, Taicher G, Mitchell AD (2010) Calibration and validation of EchoMRI whole body composition analysis based on chemical analysis of piglets, in comparison with the same for DXA. Int J Body Comp Res 8, 17-29

Mahan DC, Lepine AJ (1991) Effect of pig weaning weight and associated nursery feeding programs on subsequent performance to 105 kilograms body weight. J Anim Sci 69, 1370-1378 
Manners MJ, McCrea MR (1963) Changes in the chemical composition of sow-reared piglets during the 1st month of life. Br J Nutr 17, 495-513

Milligan BN, Fraser D, Kramer DL (2002) Within-litter birth weight variation in the domestic pig and its relation to pre-weaning survival, weight gain, and variation in weaning weights. Livest Prod Sci 76, 181-191

Mitchell AD, Scholz AM, Conway JM (1998) Body composition analysis of small pigs by dual-energy $x$-ray absorptiometry. J Anim Sci 76, 2392-2398

Mitchell AD, Ramsay TG, Scholz AM (2012) Measurement of changes in body composition of piglets from birth to $4 \mathrm{~kg}$ using quantitative magnetic resonance (QMR). Arch Tierz 55, 64-71

Morise A, Sève B, Macé K, Magliola C, Le Huërou-Luron I, Louveau I (2009) Impact of intrauterine growth retardation and early protein intake on growth, adipose tissue, and the insulin-like growth factor system in piglets. Pediatr Res 65, 45-50

Morise A, Sève B, Macé K, Magliola C, Le Huërou-Luron I, Louveau I (2011) Growth, body composition and hormonal status of growing pigs exhibiting a normal or small weight at birth and exposed to a neonatal diet enriched in proteins. Brit J Nutr 105, 1471-1479

Noblet J, Etienne M (1987) Body composition, metabolic rate and utilization of milk nutrients in suckling piglets. Reprod Nutr Dev 27, 829-839

Pond WG, Barnes RH, Bradfield RB, Kwong E, Krook L (1965) Effect of dietary energy intake on protein deficiency symptoms and body composition of baby pigs fed equalized but suboptimal amounts of protein. $J$ Nutr 85, 57-66

Poore KR, Fowden AL (2004) The effects of birth weight and postnatal growth patterns on fat depth and plasma leptin concentrations in juvenile and adult pigs. J Physiol 558, 295-304

Powell SE, Aberle ED (1980) Effects of birth weight on growth and carcass composition of swine. J Anim Sci 50, 860-868

Quiniou N, Dagorn J, Gaudré D (2002) Variation of piglets' birth weight and consequences on subsequent performance. Livest Prod Sci 78, 63-70

Rehfeldt C, Kuhn G (2006) Consequences of birth weight for postnatal growth performance and carcass quality in pigs as related to myogenesis. J Anim Sci 84, E113-E123

Rehfeldt C, Tuchscherer A, Hartung M, Kuhn G (2008) A second look at the influence of birth weight on carcass and meat quality in pigs. Meat Sci 78, 170-175

Škorjanc D, Brus M, Potokar MČ (2007) Effect of birth weight and sex on pre-weaning growth rate of piglets. Arch Tierz 50, 476-486

Vuguin PM (2007) Animal models for small for gestational age and fetal programming of adult disease. Horm Res 68,113-123

Wolter BF, Ellis M, Corrigan BP, DeDecker JM (2002) The effect of birth weight and feeding of supplemental milk replacer to piglets during lactation on preweaning and postweaning growth performance and carcass characteristics. J Anim Sci 80, 301-308

Young LG, Sharma VD (1973) Influence of energy intake by the neonatal pig on subsequent growth and development. J Anim Sci 36, 183-187

Received 18 October 2011, accepted 16 March 2012.

Corresponding author:

Armin M. Scholz

email:a.s@lmu.de

Ludwig-Maximilians-University Munich Livestock Center, Sankt Hubertusstraße 12, 85764 Oberschleißheim Germany 